\title{
A propensity score matching analysis for cardio metabolic risk of antipsychotics in patients with schizophrenia using Japanese claims data
}

Ichiro Kusumi ${ }^{1 *}$, Sachie Inoue ${ }^{2}$,Kenji Baba ${ }^{3}$, Tadashi Nosaka ${ }^{3}$ and Toshihisa Anzai ${ }^{4}$

\begin{abstract}
Background: The aim of this study was to evaluate the cardio-metabolic risk in schizophrenia patients treated by atypical antipsychotic drugs compared with that in those treated without atypical antipsychotic drugs using a nationwide insurance claims database and medical examination database in Japan.

Methods: Eligible patients were defined as those meeting the following two criteria: (i) A diagnosis of schizophrenia (ICD-10 code: F20) was made between 1 January 2005 and 31 December 2017, with data available for at least 6 months before the diagnosis was made (index month), and (ii) health check-up data were available within \pm 3 months of the index month. The primary endpoint was changes in cardio-metabolic risk based on the Suita score at 1 year, and the secondary endpoints were changes in medical examination data related to cardio-metabolic risk (total cholesterol $[\mathrm{TC}]$, triglyceride, high-density lipoprotein cholesterol, low-density lipoprotein cholesterol, body mass index [BMI], and hemoglobin A1c) at 1 year. The primary endpoint was evaluated by multivariate analysis, with the cumulative chlorpromazine equivalent amount and the baseline Suita score added as covariates.

Results: One-hundred eighty five pairs of propensity score (PS)-matched patients were evaluated. Patients receiving atypical antipsychotic drugs exhibited a greater change in the Suita score and a risk of coronary heart disease based on the Suita score of 0.530 and $0.098 \%$, respectively, than patients not receiving atypical antipsychotic drugs, but there was no significant difference ( $p=0.412$ and 0.610). The significant changes in TC and BMl were determined as $6.525 \mathrm{mg} / \mathrm{dL}$ and $0.380 \mathrm{~kg} / \mathrm{m}^{2}$ greater, respectively, in patients treated with atypical antipsychotic drugs ( $p=0.037$ and 0.011$)$.

Conclusions: There were no significant increases in changes in the Suita score at 1 year by treatment with atypical antipsychotic drugs compared with treatment without atypical antipsychotic drugs. However, the TC and BMI were significantly higher in patients treated with atypical antipsychotic drugs.
\end{abstract}

Keywords: Schizophrenia, Atypical antipsychotic drugs, Cardio-metabolic risk, Monitoring, Claim database, Propensity score matching

\footnotetext{
* Correspondence: ikusumi@med.hokudai.ac.jp

'Department of Psychiatry, Hokkaido University Graduate School of Medicine,

Kita 15, Nishi 7, Kita-ku, Sapporo, Hokkaido, Japan

Full list of author information is available at the end of the article
}

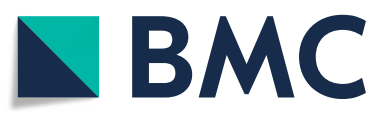

(c) The Author(s). 2020 Open Access This article is licensed under a Creative Commons Attribution 4.0 International License, which permits use, sharing, adaptation, distribution and reproduction in any medium or format, as long as you give appropriate credit to the original author(s) and the source, provide a link to the Creative Commons licence, and indicate if changes were made. The images or other third party material in this article are included in the article's Creative Commons licence, unless indicated otherwise in a credit line to the material. If material is not included in the article's Creative Commons licence and your intended use is not permitted by statutory regulation or exceeds the permitted use, you will need to obtain permission directly from the copyright holder. To view a copy of this licence, visit http://creativecommons.org/licenses/by/4.0/. The Creative Commons Public Domain Dedication waiver (http://creativecommons.org/publicdomain/zero/1.0/) applies to the data made available in this article, unless otherwise stated in a credit line to the data. 


\section{Background}

Schizophrenia is a chronic and severe mental disorder affecting 20 million people worldwide [1]. In Japan, the estimated number of patients currently receiving treatment is 795,000 and the lifetime morbidity rate is $0.7 \%$ [2]. Schizophrenia is associated with a broad array of symptoms such as hallucinations and delusions (positive symptoms), abulia and autism (negative symptoms), cognitive impairment, and affective disorder (depressive symptoms). It is associated with considerable disability, which affects educational and occupational performance. Schizophrenia is commonly seen in persons in their late teens to 30 s.

Antipsychotic drugs used in the treatment of schizophrenia are classified into two types: first-generation (typical) antipsychotic drugs, which have conventionally been used, and second-generation (atypical) antipsychotic drugs. All antipsychotic drugs block dopamine D2 receptors. Put simply, however, typical antipsychotic drugs block dopamine D2 receptors alone, whereas atypical antipsychotic drugs also act on serotonin 5-HT2A receptors and other neurotransmitters [3]. Atypical antipsychotic drugs have fewer extrapyramidal side-effects than typical antipsychotic drugs and are used as firstline antipsychotic treatment $[4,5]$. However, weight gain and impaired glucose tolerance (IGT) have developed as adverse reactions to atypical antipsychotic drugs, and there are cases in which medication is discontinued due to the onset of diabetes, ketoacidosis, or a decrease in quality of life (QOL) [6]. The blockage of receptors, such as histamine $\mathrm{H} 1$, serotonin 5 -HT2A and 5-HT2C, muscarinic $\mathrm{M} 3$, and adrenergic $\alpha 1$ and $\alpha 2$, is implicated in the onset of weight gain in patients receiving atypical antipsychotic drugs, and involvement of genetic factors has also been pointed out [7].

Leucht et al. performed a meta-analysis of the safety of antipsychotic drugs, including overall efficacy, relapse, QOL, extrapyramidal side-effects, weight gain, and sedation, in patients with different psychiatric symptoms based on 150 placebo-controlled randomized controlled trials, and reported that the standardized mean difference (SMD) in weight gain was greater with atypical antipsychotic drugs than with typical antipsychotic drugs [8]. Other studies have also reported that treatment with atypical antipsychotics in patients with schizophrenia lead to abnormal changes in metabolic parameter such as waist circumference, body mass index, and lipid or glycemic index as well as body weight, even for a short term of their use $[9,10]$. In common, these studies explain the importance of initiating and periodically continuing of monitoring when using atypical antipsychotics to in those patients in order to minimize the risk of metabolic syndrome development. Although there is evidence suggesting the effects of antipsychotic drugs on body weight gain and metabolic syndrome as described above, there is still little suggesting the relationship between atypical antipsychotic drugs and cardio-metabolic risk such as myocardial infarction or new-onset diabetes.

In this study, we hypothesized that cardio-metabolic risk is higher in schizophrenia patients treated with atypical antipsychotic drugs than in those treated without atypical antipsychotic drugs, and retrospectively examined this hypothesis using health insurance claims data and medical examination data.

\section{Methods \\ Study design}

This retrospective cohort study utilized a nationwide insurance claims database and medical examination database in Japan constructed by JMDC Inc. [11] The JMDC database is an epidemiological receipt database that has accumulated receipts (inpatient, outpatient, and dispensing) and medical examination data received from multiple employer-based health insurance associations since 2005. The cumulative dataset is approximately 5.6 million subjects as of June 2018. The database can track data for each patient in chronological order, even if the patient visited or was hospitalized at multiple medical institutions. As the database is composed of employerbased health insurance data, it contains insurance claims data of the employers and their families, and is biased in terms of age distribution, which is a point of concern. However, approximately $80 \%$ of the patients with schizophrenia in this study were younger than 65 years [12], and it was therefore reasonable to use the JMDC database for this study.

The ethics review committee secretariat of Hokkaido University stated that no ethics review was necessary for this study because it was a secondary analysis of an anonymous patient database.

\section{Study population}

From the JMDC claims database of approximately 59, 994 patients with schizophrenia, schizotypal, delusional, and other non-mood psychotic disorders (ICD-10 code: F20-29) between January 1st, 2005 and December 31st, 2017, we identified patients who were newly diagnosed with schizophrenia and for whom medical examination data were available during the period. Eligible patients were defined by meeting the following two criteria; (i) A diagnosis of schizophrenia (ICD-10 code: F20) made between January 1st, 2005 and December 31st, 2017, with data available for at least 6 months before the diagnosis was made (index month), and (ii) medical examination data were available within \pm 3 months of the index month. Patients meeting the following criteria were excluded from the study: (i) Patients with a suspected diagnosis of schizophrenia (ICD-10 code: F20); (ii) patients 
for whom an antipsychotic drug (ATC code: N05A) was prescribed within 6 months before the index month; (iii) patients who were 65 years or older at the index month; or (iv) patients for whom an anti-dementia drug (ATC code: N06D.X) was prescribed within 6 months before the index month. The exclusion criteria were defined for the following reasons: To identify patients receiving an antipsychotic drug for newly diagnosed schizophrenia [(i) and (ii)]; to exclude patients for whom an antipsychotic drug was used for delirium [(iii)]; and to exclude patients for whom an antipsychotic drug was used for dementia [(iv)]. The analysis population and treatment groups were defined by each of the study outcome.

\section{Study outcome and analysis population Primary endpoint}

The primary endpoint was changes in cardio-metabolic risk based on the Suita score at 1 year, and changes in the Suita score from baseline to 1 year were compared between groups treated with and without atypical antipsychotic drugs. The baseline was defined as the first month in which an atypical antipsychotic drug was prescribed for the group treated with atypical antipsychotic drugs, or the index month for the group treated without atypical antipsychotic drugs. The Suita score, developed by a research team at the National Cerebral and Cardiovascular Center, is a risk score to predict the 10-year risk for the development of coronary heart disease (CHD), such as myocardial infarction, in Japanese persons, and it is calculated based on age, sex, smoking habits, diabetes status, blood pressure, low-density lipoprotein cholesterol (LDL-C), high-density lipoprotein cholesterol (HDL-C), and estimated glomerular filtration rate (eGFR) [13]. The Suita score was used to calculate the risk of developing $\mathrm{CHD}$, and changes in the risk of developing CHD from baseline to 1 year were also evaluated.

Among the eligible patients, those for whom medical examination data were available within \pm 3 months of 1 year after the index month and the calculation of the Suita score was possible (medical examination follow-up population) were subjected to evaluation of the primary endpoint. The group treated with atypical antipsychotic drugs was defined as patients for whom an atypical antipsychotic drug was prescribed in the index month or the following month and the medication was not switched to a typical antipsychotic drug. The group treated without atypical antipsychotic drugs was defined as patients for whom no atypical antipsychotic drug was prescribed within 12 months from baseline.

\section{Secondary endpoint}

The secondary endpoints were changes in medical examination data related to cardio-metabolic risk from baseline until 1 year, changes in the Framingham and
Japan Arteriosclerosis Longitudinal Study (JALS) scores from baseline until 1 year, and the risk of developing diabetes, cardiovascular events, and cardiovascular death during the observation period. The medical examination data for cardio-metabolic risk were total cholesterol (TC), triglyceride (TG), HDL-C, LDL-C, body mass index (BMI), and hemoglobin $\mathrm{A} 1 \mathrm{c}(\mathrm{HbA} 1 \mathrm{c})$, and they were evaluated using medical examination data at baseline and 1 year. The Framingham score and JALS score are risk scores to predict the risk for the development of CHD $[14,15]$, and the scores were calculated using medical examination data. The onset of diabetes was defined as the diagnosis of diabetes (ICD-10 code: E10-14) and the prescription of anti-diabetes drugs (ATC code: A10) after baseline. Cardiovascular events included myocardial infarction, stroke, and hospitalization for heart failure, and patients were considered to have a cardiovascular event if they had myocardial infarction (ICD-10 code: I21) or underwent surgery for myocardial infarction, if they were diagnosed with stroke (ICD-10 code: I61.4, I61.9, I63.3I63.9, and I64), or if they were hospitalized for heart failure (ICD-10 code: I11.0, I50.0, I50.1, and I50.9) after baseline. Cardiovascular deaths were defined as deaths among those with cardiovascular events.

Biomarkers, and Framingham and JALS scores were evaluated in the medical examination follow-up population. Onset of diabetes, cardiovascular events and cardiovascular death were analyzed in all eligible patients (long-term follow-up population). In the long-term follow-up population, the group treated with atypical antipsychotic drugs was defined as patients for whom an atypical antipsychotic drug was prescribed in the index month or the following month (excluding as-needed usage), and the group treated without atypical antipsychotic drugs was defined as patients for whom an atypical antipsychotic drug was not prescribed in the index month or the following month.

\section{Clinical monitoring}

The frequency of monitoring diabetes and lipid markers was also evaluated to determine whether physicians treating schizophrenia monitored diabetes and dyslipidemia regularly. Diabetes monitoring was defined as follows: "Urinary qualitative/semi-quantitative examination (general substances)," "HbA1c measurement," or "measurement of glycated albumin or 1,5-anhydro-D-glucitol" was performed at the hospital where schizophrenia was diagnosed or at the medical institution where an antipsychotic drug was administered. Lipid marker monitoring was defined as follows: Biochemical examinations of blood (medical remuneration code: D007) conducted at the institution where schizophrenia was diagnosed or atypical antipsychotic was prescribed. 


\section{Statistical analysis}

To reduce the effects of potential confounding factors in this observational study, a propensity score (PS) matching analysis was applied in both the medical examination follow-up population and the long-term follow-up population. PS matching reduces bias due to confounding factors by matching patients on baseline variables using a multivariable logistic regression model. Confounding factors of patient characteristics were examined based on clinical findings, theoretical grounds, and findings from previous studies [16, 17]. The candidate factors examined are shown in the Additional file. Candidate factors were narrowed down by the following procedure: (1) Diseases that had affected a higher proportion of patients or drugs with a high prescription rate (2\% or higher); (2) presence of biases between the two groups $(p<0.25$ for between-group difference); and (3) among variables satisfying (1) and (2) above, those clinically related to each other (eg, "antidepressant use" and "depression") were narrowed down to a single variable. The following factors were selected: sex, year of diagnosis, history of diabetes, age at baseline, systolic blood pressure, LDL-C, prescription of corticosteroids or antidepressants during the 1 month before baseline, hyperthyroidism, chronic hepatitis, myocardial infarction or other $\mathrm{CHD}$, heart failure, peripheral vascular disease, and cancer other than risk factors during the 6 months before baseline. The PS matching pairs were created at a ratio of 1:1 based on the nearest neighbor matching algorithm with a 0.25 caliper distance with no replacements. The goodness-of-fit of the logistic regression model was evaluated by the Hosmer-Lemeshow test. Discrimination, ie, the capability to classify individuals with and without events, was evaluated by the $\mathrm{C}$-statistic or the area under the receiving operating characteristic curve [18]. A C-statistic $>0.7$ indicates good discrimination.

Regarding the primary endpoint, changes in the Suita score from baseline to 1 year and the difference in event incidence risk calculated from the score are presented as the mean \pm standard deviation (SD). The relationship was evaluated by multivariate analysis using changes in the Suita score from baseline to 1 year and the difference in event incidence risk calculated from the score as the objective variables, and the presence of a new prescription of an atypical antipsychotic drug as an explanatory

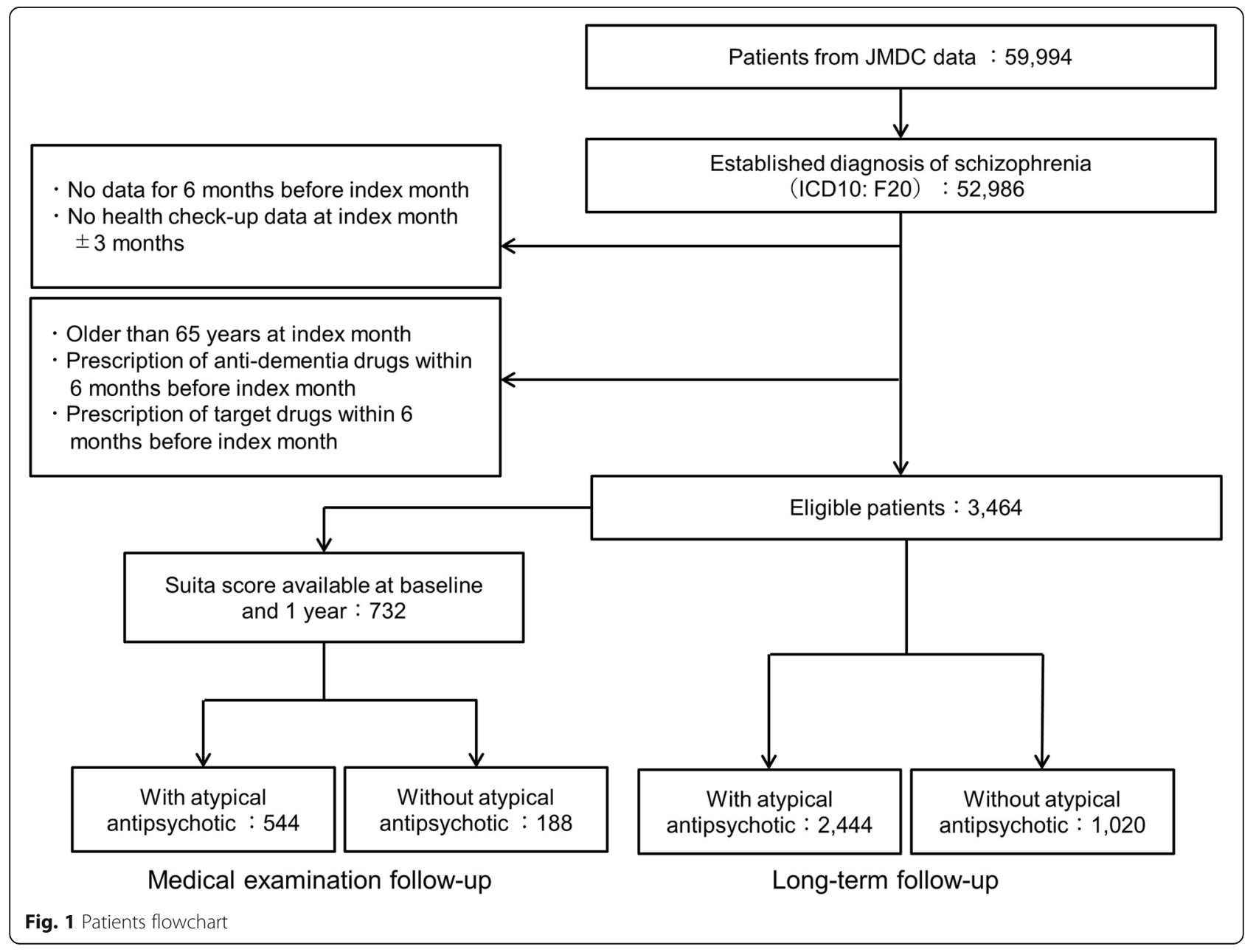


variable, with the cumulative chlorpromazine equivalent amount and the baseline Suita score added as covariates.

Changes in several medical examination data at 1 year as a secondary endpoint are also presented as the mean \pm SD. In addition, multivariate analysis was performed using changes in each medical examination data at 1 year as the objective variable and the presence of a new prescription of an atypical antipsychotic drug as an explanatory variable, with the cumulative chlorpromazine equivalent amount and medical examination data values at baseline added as covariates. Cox's proportional hazards model was used to calculate the hazard ratios for the onset of diabetes, cardiovascular events, and cardiovascular death during the observation period in the group treated with atypical antipsychotic drugs compared with that treated without atypical antipsychotic drugs, with the presence of a new prescription of an atypical antipsychotic drug as an explanatory variable. The cumulative chlorpromazine equivalent was adjusted as a covariate.

In the evaluation of the frequency of monitoring diabetes and lipid markers, between-group comparisons

Table 1 Patient characteristics

\begin{tabular}{|c|c|c|c|c|c|c|}
\hline & \multicolumn{2}{|c|}{ Eligible patients } & \multicolumn{2}{|c|}{$\begin{array}{l}\text { Medical examination follow-up } \\
\text { patients (PS matched) }\end{array}$} & \multicolumn{2}{|c|}{$\begin{array}{l}\text { Long-term follow-up patients } \\
\text { (PS matched) }\end{array}$} \\
\hline & $\begin{array}{l}\text { With atypical } \\
\text { antipsychotic } \\
(N=2444)\end{array}$ & $\begin{array}{l}\text { Without atypical } \\
\text { antipsychotic } \\
(N=1020)\end{array}$ & $\begin{array}{l}\text { With atypical } \\
\text { antipsychotic } \\
(N=185)\end{array}$ & $\begin{array}{l}\text { Without atypical } \\
\text { antipsychotic } \\
(N=185)\end{array}$ & $\begin{array}{l}\text { With atypical } \\
\text { antipsychotic } \\
(N=889)\end{array}$ & $\begin{array}{l}\text { Without atypical } \\
\text { antipsychotic } \\
(N=889)\end{array}$ \\
\hline \multicolumn{7}{|l|}{ Age } \\
\hline$<25$ years & 131 (5.4\%) & $51(5.0 \%)$ & 0 & 0 & $14(1.6 \%)$ & $26(2.9 \%)$ \\
\hline 25-29years & $244(10.0 \%)$ & 67 (6.6\%) & 0 & 0 & 47 (5.3\%) & $54(6.1 \%)$ \\
\hline 30-34 years & $280(11.5 \%)$ & 88 (8.6\%) & 0 & 0 & 67 (7.5\%) & $76(8.6 \%)$ \\
\hline 35-39years & 353 (14.4\%) & $108(10.6 \%)$ & $38(20.5 \%)$ & 28 (15.1\%) & $112(12.6 \%)$ & 99 (11.1\%) \\
\hline 40-49 years & 947 (38.8\%) & $369(36.2 \%)$ & 85 (46\%) & 91 (49.2\%) & 381 (42.9\%) & 345 (38.8\%) \\
\hline 50-59 years & $443(18.1 \%)$ & $279(27.4 \%)$ & 55 (29.7\%) & 59 (31.9\%) & 235 (26.4\%) & 245 (27.6\%) \\
\hline$>=60$ years & $46(1.9 \%)$ & $58(5.7 \%)$ & 7 (3.8\%) & 7 (3.8\%) & 33 (3.7\%) & $44(5 \%)$ \\
\hline Mean (years) & $40.9 \pm 9.8$ & $43.9 \pm 10.5$ & $46.3 \pm 7$ & $47.0 \pm 6.8$ & $44.4 \pm 9.1$ & $44.3 \pm 9.8$ \\
\hline Sex (male \%) & 1608 (65.8\%) & $676(66.3 \%)$ & $127(68.6 \%)$ & 133 (71.9\%) & 594 (66.8\%) & $570(64.1 \%)$ \\
\hline \multicolumn{7}{|l|}{ Year of diagnosis } \\
\hline-2007 & $25(1.0 \%)$ & 15 (1.5\%) & 0 & 0 & $6(0.7 \%)$ & $6(0.7 \%)$ \\
\hline 2008-2010 & 327 (13.4\%) & $83(8.1 \%)$ & $16(8.7 \%)$ & $21(11.4 \%)$ & $69(7.8 \%)$ & 70 (7.9\%) \\
\hline 2011-2013 & $693(28.4 \%)$ & $249(24.4 \%)$ & 62 (33.5\%) & 47 (25.4\%) & 229 (25.8\%) & $226(25.4 \%)$ \\
\hline 2014- & 1399 (57.2\%) & $673(66 \%)$ & $107(57.8 \%)$ & $117(63.2 \%)$ & 585 (65.8\%) & 587 (66\%) \\
\hline SBP (mmHg) & $118.2 \pm 15.4$ & $119.6 \pm 16.3$ & $120.5 \pm 14.9$ & $121.1 \pm 16.4$ & $119.5 \pm 16.3$ & $119.1 \pm 16$ \\
\hline $\mathrm{DBP}(\mathrm{mmHg})$ & $72.9 \pm 11.4$ & $73.9 \pm 11.5$ & $75.1 \pm 10.9$ & $75.8 \pm 12.2$ & $74.3 \pm 11.7$ & $73.9 \pm 11.4$ \\
\hline LDL-C (mg/dL) & $119.6 \pm 32.5$ & $118.4 \pm 32.5$ & $118.6 \pm 29.4$ & $123 \pm 32.1$ & $118.4 \pm 31.6$ & $118.7 \pm 32.1$ \\
\hline $\mathrm{HDL}-\mathrm{C}(\mathrm{mg} / \mathrm{dL})$ & $62.8 \pm 17.5$ & $62.3 \pm 17.0$ & $63.3 \pm 16.4$ & $62.2 \pm 15.8$ & $62.6 \pm 18$ & $62.7 \pm 16.8$ \\
\hline eGFR (mL/min/1.73 m²) & $98.3 \pm 18.1$ & $96.7 \pm 19.5$ & $92.7 \pm 16.4$ & $94.7 \pm 18.3$ & $96.7 \pm 17.7$ & $97.5 \pm 19$ \\
\hline HbA1c (\%) & $5.5 \pm 0.6$ & $5.5 \pm 0.8$ & $5.6 \pm 0.7$ & $5.5 \pm 0.6$ & $5.5 \pm 0.7$ & $5.5 \pm 0.7$ \\
\hline TC (mg/dL) & $205.5 \pm 39.0$ & $203.1 \pm 38.4$ & $205.2 \pm 33.9$ & $207.6 \pm 35.9$ & $204 \pm 38.5$ & $203.4 \pm 37.3$ \\
\hline TG (mg/dL) & $120.5 \pm 106.9$ & $118 \pm 100.3$ & $126.8 \pm 131$ & $123.8 \pm 85.9$ & $119.8 \pm 105.5$ & $115.4 \pm 86.9$ \\
\hline BMI $\left(\mathrm{kg} / \mathrm{m}^{2}\right)$ & $22.8 \pm 3.9$ & $22.9 \pm 4.0$ & $23.4 \pm 3.9$ & $23.4 \pm 4.3$ & $23 \pm 4.1$ & $22.9 \pm 4$ \\
\hline Suita score (LDL) & $30.5 \pm 10.4$ & $32.8 \pm 11.0$ & $31.4 \pm 10.4$ & $32.7 \pm 10.3$ & $31.8 \pm 10.4$ & $32.2 \pm 10.9$ \\
\hline Framingham score (LDL) & $0.2 \pm 5.0$ & $1.2 \pm 5.0$ & $1.1 \pm 4.3$ & $1.7 \pm 4.1$ & $1.0 \pm 4.8$ & $1.0 \pm 5.1$ \\
\hline JALS score & $20.3 \pm 15.3$ & $22.6 \pm 16.1$ & $21.1 \pm 14.7$ & $22.1 \pm 14.9$ & $21.2 \pm 14.9$ & $21.8 \pm 15.9$ \\
\hline Smoking habits & $646(26.4 \%)$ & $274(26.9 \%)$ & $51(27.6 \%)$ & $52(28.1 \%)$ & $245(27.6 \%)$ & $246(27.7 \%)$ \\
\hline Diabetes & $88(3.6 \%)$ & $60(5.9 \%)$ & $13(7 \%)$ & $5(2.7 \%)$ & $46(5.2 \%)$ & 44 (4.9\%) \\
\hline
\end{tabular}

PS Propensity score, SBP Systolic blood pressure, DBP Diastolic blood pressure, $L D L-C$ Low-density lipoprotein cholesterol, $H D L-C$ High-density lipoprotein cholesterol, eGFR Estimated glomerular filtration rate, HbA1c Hemoglobin A1c, TC Total cholesterol, TG Triglyceride, BMI Body mass index, JALS Japan Arteriosclerosis Longitudinal Study 
Table 2 Change in Suita score for 1 year. Mean change from baseline

\begin{tabular}{|c|c|c|c|c|c|c|}
\hline & \multicolumn{3}{|c|}{ With atypical antipsychotic } & \multicolumn{3}{|c|}{ Without atypical antipsychotic } \\
\hline & $\mathbf{N}$ & Mean & SD & $\mathrm{N}$ & Mean & SD \\
\hline Change in Suita score (LDL) & 185 & 1.416 & 6.322 & 185 & 0.681 & 5.494 \\
\hline
\end{tabular}

LDL Low-density lipoprotein, SD Standard deviation

were performed using the Student's t-test as appropriate. All data analyses were carried out with SAS v.9.4, and $P$ values of $<0.05$ were considered significant.

\section{Results}

\section{Study population and analysis population}

A flow chart of the study population is shown in Fig. 1. In the JMDC database, 52,986 patients having schizophrenia (F20) were identified during the study period. Of them, 3464 patients who were newly diagnosed with schizophrenia and having medical examination data were identified as eligible patients. The numbers of patients treated with and without atypical antipsychotic drugs at baseline were 2444 and 1020, respectively (long-term follow-up population). Of these, the number of patients who had baseline and 1-year Suita scores (i.e., medical examination follow-up population) was 732 . The number of patients evaluated for the primary endpoint was 544 and 188 in the group treated with and without atypical antipsychotic drugs, respectively (Fig. 1).

Among the eligible patients $(n=3464)$, logistic regression analysis was performed for PS matching. SMDs of some covariates between with and without atypical antipsychotic groups in PS matched population were over 0.1 . However, since the distribution of propensity score of the two groups were well overlapped, it was evaluated that the covariates were balanced after PS matching based on a comprehensive judgement. The model was well-calibrated (Hosmer-Lemeshow test $=0.512$ ) and demonstrated good discrimination $(\mathrm{C}$-statistic $=0.770)$. The characteristics of PS-matched medical examination follow-up patients ( $n=370,185$ pairs of patients), and PS-matched long-term follow-up patients $(n=1778,889$ pairs of patients) were summarized in Table 1 . The mean age of the PS-matched medical examination follow-up patients was 47 years, and male patients accounted for approximately $70 \%$. Laboratory values were generally within the normal range. The proportions of patients with a history of diabetes and smoking habits were 4.9 and $27.8 \%$, respectively.

\section{Primary endpoint}

The changes in the Suita score at 1 year were $1.4 \pm 6.3$ and $0.7 \pm 5.5$ in the group treated with and without atypical antipsychotic drugs, respectively (mean $\pm \mathrm{SD}$ ). On multivariate analysis, the changes in the Suita score and the estimated CHD risk based on the Suita score were 0.530 and $0.098 \%$ greater, respectively, in the group treated with atypical antipsychotic drugs, but there was no significant difference $(p=0.412$ and 0.610 , adjusted for cumulative chlorpromazine equivalent amount and the baseline Suita score) (Tables 2 and 3).

\section{Secondary endpoint}

The changes in medical examination data (TC, TG, HDLC, LDL-C, BMI, and HbA1c) at 1 year in the group treated with and without atypical antipsychotic drugs were $7.049 \pm 31.308 \mathrm{mg} / \mathrm{dL}$ and $1.133 \pm 30.177 \mathrm{mg} / \mathrm{dL}$ (TC), $5.589 \pm 130.910 \mathrm{mg} / \mathrm{dL}$ and $5.173 \pm 103.008 \mathrm{mg} / \mathrm{dL}$ (TG), $-0.568 \pm 12.582 \mathrm{mg} / \mathrm{dL} \quad$ and $-0.346 \pm 10.109 \mathrm{mg} / \mathrm{dL}$ (HDL-C), $6.130 \pm 25.689 \mathrm{mg} / \mathrm{dL}$ and $0.454 \pm 25.469 \mathrm{mg} / \mathrm{dL}$ (LDL-C), $\quad 0.618 \pm 1.320 \mathrm{~kg} / \mathrm{m}^{2}$ and $0.123 \pm 1.315 \mathrm{~kg} / \mathrm{m}^{2}$ (BMI), and $-0.051 \pm 0.350 \%$ and $0.059 \pm 0.036 \%$ (HbA1c), respectively (mean $\pm \mathrm{SD}$ ) (Tables 4, 5, 6, 7 and 8). The changes in the Framingham and JALS scores at 1 year were $0.562 \pm 2.335$ and $0.286 \pm 1.967$, and $2.433 \pm 8.329$ and 1.452 \pm 7.427 , respectively (Table 8 ).

Based on multivariate analysis adjusted for the cumulative chlorpromazine equivalent amount and baseline $\mathrm{TC}$

Table 3 Change in Suita score for 1 year. Results of multivariate analysis $(N=370)$

\begin{tabular}{|c|c|c|c|}
\hline Variable & Estimate & $95 \% \mathrm{Cl}$ & $P$-value \\
\hline \multicolumn{4}{|l|}{ Change in Suita score (LDL) } \\
\hline With atypical antipsychotic & 0.530 & $(-0.738,1.798)$ & 0.412 \\
\hline Cumulative chlorpromazine equivalent & -0.003 & $(-0.221,0.216)$ & 0.980 \\
\hline Baseline Suita score (LDL) & -0.167 & $(-0.224,-0.111)$ & $<.0001$ \\
\hline \multicolumn{4}{|l|}{ Change in CHD risk by Suita score (LDL) (\%) } \\
\hline With atypical antipsychotic & 0.098 & $(-0.280,0.477)$ & 0.610 \\
\hline Cumulative chlorpromazine equivalent & 0.018 & $(-0.047,0.083)$ & 0.589 \\
\hline Baseline Suita score (LDL) & -0.030 & $(-0.047,-0.013)$ & 0.001 \\
\hline
\end{tabular}


Table 4 Change in TC for 1 year. Mean change from baseline

\begin{tabular}{llllllll}
\hline & \multicolumn{3}{l}{$\begin{array}{l}\text { With atypical } \\
\text { antipsychotic }\end{array}$} & & \multicolumn{3}{l}{$\begin{array}{l}\text { Without atypical } \\
\text { antipsychotic }\end{array}$} \\
\cline { 2 - 3 } & $\mathbf{N}$ & Mean & SD & & N & Mean & SD \\
\hline Change in TC $(\mathrm{mg} / \mathrm{dl})$ & 185 & 7.049 & 31.308 & & 185 & 1.133 & 30.177 \\
\hline TC Total cholesterol, SD Standard deviation & & & & &
\end{tabular}

or BMI, the changes in TC and BMI were $6.525 \mathrm{mg} / \mathrm{dL}$ and $0.380 \mathrm{~kg} / \mathrm{m}^{2}$ greater, respectively, in the group treated with atypical antipsychotic drugs, and the differences were significant ( $p=0.037$ and 0.011) (Tables 4, 5, 6 and 7). The change in LDL-C was $5.537 \mathrm{mg} / \mathrm{dL}$ greater in the group treated with atypical antipsychotic drugs, although there was no significant difference $(p=0.058)$ (Table 8).

There were no significant differences between the two groups in other biomarkers, Framingham score, JALS score, or the onset of diabetes, cardiovascular events, or cardiovascular death (Tables 8 and 9).

\section{Clinical monitoring}

The frequency of monitoring for diabetes and lipid markers in eligible patients $(n=3464)$ was 0.028 times per month (once every 35 to 36 months) and 0.078 times per month (once every 12 to 13 months), respectively, with an average of 0.336 and 0.936 times per patient per annum. There was no significant difference in the frequency of monitoring between treatment groups in the primary endpoint analysis population $(p=0.567$ and 0.080 ) (Tables 10 and 11). Seventy-seven and $58 \%$ of patients did not have monitoring for diabetes and lipid markers, respectively.

\section{Discussion}

In this study, we evaluated the difference in cardiometabolic risk between schizophrenia patients treated with and without atypical antipsychotic drugs using a Japanese employment-based health insurance database. Changes in the Suita score from baseline to 1 year were the primary outcome and were used as an assessment index for cardio-metabolic risk. Our analysis revealed that the changes in the Suita score and risk calculated based on these changes were 0.530 and $0.098 \%$ greater, respectively, in the group treated with atypical antipsychotic drugs than in the group treated

Table 5 Change in TC for 1 year. Results of multivariate analysis $(N=370)$

\begin{tabular}{lllll}
\hline Variable & Estimate & $\mathbf{9 5 \% C l}$ & & $\boldsymbol{P}$-value \\
\hline With atypical antipsychotic & 6.525 & $(0.406$, & $12.643)$ & 0.037 \\
$\begin{array}{l}\text { Cumulative chlorpromazine } \\
\text { equivalent }\end{array}$ & -0.686 & $(-1.736$, & $0.363)$ & 0.199 \\
Baseline TC & -0.399 & $(-0.480$, & $-0.319)$ & $<.0001$ \\
\hline
\end{tabular}

TC Total cholesterol, Cl Confidence interval
Table 6 Change in BMI for 1 year. Mean change from baseline

\begin{tabular}{|c|c|c|c|c|c|c|}
\hline & \multicolumn{3}{|c|}{$\begin{array}{l}\text { With atypical } \\
\text { antipsychotic }\end{array}$} & \multicolumn{3}{|c|}{$\begin{array}{l}\text { Without atypical } \\
\text { antipsychotic }\end{array}$} \\
\hline & $\mathrm{N}$ & Mean & SD & $\mathrm{N}$ & Mean & SD \\
\hline Change in BMI $\left(\mathrm{kg} / \mathrm{m}^{2}\right)$ & 185 & 0.618 & 1.320 & 185 & 0.123 & 1.315 \\
\hline
\end{tabular}

$B M I$ Body mass index, SD Standard deviation

without atypical antipsychotic drugs, but there was no significant difference $(p=0.412$ and 0.610$)$. The changes in TC and BMI evaluated as secondary outcomes for cardio-metabolic risk were $6.525 \mathrm{mg} / \mathrm{dL}$ and $0.380 \mathrm{~kg} / \mathrm{m}^{2}$ greater, respectively, in patients treated with atypical antipsychotic drugs, and the differences were significant $(p=0.037$ and 0.011$)$. Other outcomes did not show any significant differences between the two groups.

Calculation of Suita scores requires information on laboratory values and lifestyle (smoking). As the JMDC database generally includes only claims data on medical institutions, our inclusion criteria inevitably specified that there should have information of medical examinations for patients to be subjected to analysis, and this requirement raises concerns about the external validity of the analysis population. Meanwhile, it is thought that the execution bias could be reduced because those information of medical examinations were not ordered actively deemed to be necessary from the medical institutions. The analysis population in the present study did not differ markedly from those in previous Japanese clinical studies in age, HbA1c, systolic blood pressure, $\mathrm{TC}$, or BMI, with no notable heterogeneity compared with the populations of schizophrenia patients in hitherto reported clinical studies [19-24]. The proportion of male patients was slightly higher in our analysis population. However, subgroup analysis by sex revealed no significant difference in changes in the Suita score between patients treated with and without atypical antipsychotic drugs (male patients: $p=0.591$; female patients: $p=$ $0.471)$.

In this analysis, there was no effect on changes in the Suita score due to the administration of atypical antipsychotic drugs. One reason may be the limited number of patients and the limited evaluation period. However, the validity of the number of patients was

Table 7 Change in BMI for 1 year. Results of multivariate analysis $(N=370)$

\begin{tabular}{lllll}
\hline Variable & Estimate & $\mathbf{9 5 \% C l}$ & & $\boldsymbol{P}$-value \\
\hline With atypical antipsychotic & 0.380 & $(0.090$, & $0.670)$ & 0.011 \\
$\begin{array}{l}\text { Cumulative chlorpromazine } \\
\text { equivalent }\end{array}$ & 0.048 & $(-0.001$, & $0.098)$ & 0.057 \\
Baseline BMI & -0.047 & $(-0.080$, & $-0.015)$ & 0.004 \\
\hline
\end{tabular}

$B M I$ Body mass index, $\mathrm{Cl}$ Confidence interval 
Table 8 Change in other outcomes for 1 year

\begin{tabular}{|c|c|c|c|c|c|c|c|c|}
\hline \multirow[t]{2}{*}{ Outcome } & \multirow[t]{2}{*}{ Group } & \multicolumn{3}{|c|}{ Change from baseline } & \multicolumn{4}{|c|}{ Multivariate analysis } \\
\hline & & $\mathbf{N}$ & Mean & SD & Estimate & $95 \% \mathrm{Cl}$ & & $P$-value \\
\hline \multirow[t]{2}{*}{ TG (mg/dl) } & With atypical antipsychotic & 185 & 5.589 & 130.910 & 8.669 & $(-13.141$ & 30.478) & 0.435 \\
\hline & Without atypical antipsychotic & 185 & 5.173 & 103.008 & - & - & - & - \\
\hline \multirow[t]{2}{*}{ HDL-C (mg/dl) } & With atypical antipsychotic & 185 & -0.568 & 12.582 & 0.104 & $(-2.359$ & $2.566)$ & 0.934 \\
\hline & Without atypical antipsychotic & 185 & -0.346 & 10.109 & - & - & - & - \\
\hline \multirow[t]{2}{*}{ LDL-C (mg/dl) } & With atypical antipsychotic & 185 & 6.130 & 25.689 & 5.537 & $(-0.178$ & 11.253) & 0.058 \\
\hline & Without atypical antipsychotic & 185 & 0.454 & 25.469 & - & - & - & - \\
\hline \multirow[t]{2}{*}{ HbA1c (\%) } & With atypical antipsychotic & 144 & -0.051 & 0.350 & -0.075 & $(-0.159$ & $0.008)$ & 0.075 \\
\hline & Without atypical antipsychotic & 145 & 0.059 & 0.360 & - & - & - & - \\
\hline \multirow[t]{2}{*}{ Framingham score (LDL) } & With atypical antipsychotic & 185 & 0.562 & 2.335 & 0.224 & $(-0.246$ & $0.693)$ & 0.349 \\
\hline & Without atypical antipsychotic & 185 & 0.286 & 1.967 & - & - & - & - \\
\hline \multirow[t]{2}{*}{ JALS score } & With atypical antipsychotic & 147 & 2.433 & 8.329 & 1.442 & $(-0.435$ & 3.319) & 0.132 \\
\hline & Without atypical antipsychotic & 157 & 1.452 & 7.427 & - & - & - & - \\
\hline
\end{tabular}

TG Triglyceride, HDL-C High-density lipoprotein cholesterol, LDL-C Low-density lipoprotein cholesterol, HbA1c Hemoglobin A1c, JALS Japan Arteriosclerosis Longitudinal Study, SD Standard deviation, CI Confidence interval

unable to be sufficiently assessed as this was the first study to evaluate 1-year changes in the Suita score in Japanese patients.

Regarding the changes in TC and BMI at 1 year, significant increases $\left(+6.525 \mathrm{mg} / \mathrm{dL}\right.$ and $+0.380 \mathrm{~kg} / \mathrm{m}^{2}$, respectively) were observed in patients treated with atypical antipsychotic drugs. However, these increases were only within the normal range and it took 1 year for the changes to occur. It is therefore controversial whether they can be considered a clinically significant increase in cardiovascular risk. However, Someya et al. reported that even a slight increase in BMI within the normal range at around age 20 may predispose one to type 2 diabetes in middle age (32 years later) (The risk of type 2 diabetes was 1.77-times higher in persons with a BMI of $\geq 21 \mathrm{~kg} / \mathrm{m}^{2}$ and $<22 \mathrm{~kg} / \mathrm{m}^{2}, 2.42$-times higher in persons with a BMI of $\geq 22 \mathrm{~kg} / \mathrm{m}^{2}$ and $<23 \mathrm{~kg} / \mathrm{m}^{2}$, and 2.53-times higher in persons with a BMI of $\geq 23 \mathrm{~kg} / \mathrm{m}^{2}$ than in persons with a BMI of $<21 \mathrm{~kg} / \mathrm{m}^{2}$ ) [25]. Accordingly, further risk assessment is warranted, including long-term outcomes such as cardiovascular events and new-onset diabetes.

The medical examination data requiring the utmost attention in evaluating cardio-metabolic risk is LDL-C, and there was no significant difference in changes in LDL-C between the two groups. However, compared with other clinical studies evaluating 1-year changes in LDL-C due to antipsychotic drugs [26-28], the changes in our analysis population were similar or slightly larger than there results $(6.130 \mathrm{mg} / \mathrm{dL}$ in patients treated with atypical antipsychotic drugs and $0.454 \mathrm{mg} / \mathrm{dL}$ in patients treated without atypical antipsychotic drugs). Our results were obtained in a real-world setting not a strict treatment environment, which highlights the importance of medical examination data monitoring in clinical settings. The mean annual frequency of monitoring diabetes and lipid markers in the eligible patients in this study was 0.336 and 0.936 times per patient (ie, once every 3 years and once a year) and the rate of untested patients during the follow-up period was 76.6 and $57.8 \%$, respectively,

Table 9 Event rate

\begin{tabular}{|c|c|c|c|c|c|c|c|c|}
\hline Event & Group & $\mathbf{N}$ & Mean follow-up (months) & Number of events & $\mathrm{HR}^{\mathrm{a}}$ & $95 \% \mathrm{Cl}$ & & $P$-value \\
\hline \multirow[t]{2}{*}{ Diabetes } & With atypical antipsychotic & 746 & 8.60 & 10 & 1.377 & $(0.536$ & 3.539) & 0.506 \\
\hline & Without atypical antipsychotic & 752 & 25.38 & 12 & (reference) & - & - & - \\
\hline \multirow[t]{2}{*}{ CV events } & With atypical antipsychotic & 889 & 8.62 & 12 & 1.010 & $(0.455$ & $2.240)$ & 0.981 \\
\hline & Without atypical antipsychotic & 889 & 24.75 & 20 & (reference) & - & - & - \\
\hline \multirow[t]{2}{*}{ CV death } & With atypical antipsychotic & 889 & 8.70 & 0 & $N A^{b}$ & NA & NA & NA \\
\hline & Without atypical antipsychotic & 889 & 25.36 & 1 & NA & NA & NA & NA \\
\hline
\end{tabular}

CV Cardiovascular; HR Hazard ratio, Cl Confidence interval, NA Not applicable

${ }^{a} \mathrm{HR}$ was estimated by Cox's proportional hazards model. Cumulative chlorpromazine equivalent was adjusted as a covariate

${ }^{\mathrm{b}} \mathrm{HR}$ was unable to be estimated due to the lack of events 
Table 10 Frequency of clinical monitoring. Diabetes

\begin{tabular}{llllll}
\hline Population & \multicolumn{2}{l}{$\begin{array}{l}\text { Frequency of diabetes } \\
\text { monitoring (times/month) }\end{array}$} & \multirow{2}{*}{$\begin{array}{l}\boldsymbol{P} \text { - } \\
\text { value }\end{array}$} \\
\cline { 2 - 4 } & $\mathbf{N}$ & Mean & SD & \\
\hline Eligible patients & $2968^{\mathrm{b}}$ & 0.028 & 0.099 & - \\
Primary analysis population (PS matched) & & & \\
With atypical antipsychotic & 185 & 0.022 & 0.064 & 0.567 \\
Without atypical antipsychotic & 185 & 0.026 & 0.072 & \\
\hline
\end{tabular}

PS Propensity score, SD Standard deviation

${ }^{a}$ Eligible patients: total months of examination/total months from index month to the last month available in claims data; Primary analysis population: total months of examination/12 months

${ }^{b}$ Patients with diabetes at index month were excluded

suggesting that these medical examination data are not satisfactorily monitored in actual clinical settings. Promotion of the periodic monitoring of blood glucose levels, lipid markers, etc. is important to improve antipsychotic drug treatment.

Several limitations in the present study need to be considered. First, the present analysis focused on health insurance claims data that did not include medical record information. Therefore, not all patients for whom an antipsychotic drug was used on an off-label basis were excluded from the analysis, although we precluded such patients as much as possible by defining the exclusion criteria. Second, the frequency of diabetes monitoring was low, which raises the possibility that the presence of diabetes (defined as fasting plasma glucose $\geq 7.0 \mathrm{mmol} / \mathrm{L}(126 \mathrm{mg} /$ dl) or use of any glucose-lowering drug) as a variable for the calculation of Suita scores was underestimated. The medical information databases currently available in Japan do not contain sufficient data regarding clinical laboratory values to achieve the purpose of this study, and it is hoped that a nationwide medical information database including these clinical data will be constructed in the future.

Table 11 Frequency of clinical monitoring. Lipid markers

\begin{tabular}{lllll}
\hline Population & \multicolumn{3}{l}{$\begin{array}{l}\text { Frequency of lipid marker } \\
\text { monitoring (times/month) }\end{array}$} & \multirow{2}{*}{$\begin{array}{l}\boldsymbol{P} \text { - } \\
\text { value }\end{array}$} \\
\cline { 2 - 4 } & $\mathbf{N}$ & Mean & SD & \\
\hline Eligible patients & 3464 & 0.078 & 0.184 & - \\
$\begin{array}{lllll}\text { Primary analysis population (PS matched) } \\
\text { With atypical antipsychotic }\end{array}$ & 185 & 0.051 & 0.123 & 0.080 \\
Without atypical antipsychotic & 185 & 0.076 & 0.147 &
\end{tabular}

PS Propensity score, SD Standard deviation

${ }^{a}$ Eligible patients: total months of examination/total months from index month to the last month available in claims data; Primary analysis population: total months of examination/12 months

\section{Conclusions}

In this study, significant increases in changes in the Suita score at 1 year by atypical antipsychotic drugs use were not observed, but there were significant increases in TC and BMI in patients treated with atypical antipsychotic drugs.

\section{Supplementary Information}

The online version contains supplementary material available at https://doi. org/10.1186/s12888-020-02987-1.

Additional file 1: Supplementary Table. Risk factors considered in

propensity scoring.

\section{Abbreviations}

BMI: Body mass index; CHD: Coronary heart disease; Cl: Confidence interval; eGFR: Estimated glomerular filtration rate; HbA1c: Hemoglobin A1c; HDL-

C: High-density lipoprotein cholesterol; IGT: Impaired glucose tolerance; JALS: Japan Arteriosclerosis Longitudinal Study; LDL-C: Low-density lipoprotein cholesterol; PS: Propensity score; QOL: Quality of life; SD: Standard deviation; SMD: Standardized mean difference; TC: Total cholesterol; TG: Triglyceride

\section{Acknowledgments}

Not applicable.

\section{Authors' contributions}

All authors (IK, SI, KB, TN, and TA) participated in the interpretation of study results, and in the drafting, critical revision, and approval of the final version of the manuscript. IK, KB, TN and TA were involved in development of the study design, and SI conducted data analyses.

\section{Funding}

This study was funded by Sumitomo Dainippon Pharma.

\section{Availability of data and materials}

The datasets generated and/or analyzed during the current study are not publicly available because it was purchased from a commercial provider (JMDC Inc.), but it is available from the corresponding author on reasonable request.

\section{Ethics approval and consent to participate}

The ethics review committee of Hokkaido University stated that no ethics review was necessary for this study and waived the need for formal ethics approval because it was a secondary analysis of an anonymous patient database.

\section{Consent for publication}

Not applicable.

\section{Competing interests}

IK has received honoraria from Astellas, Daiichi Sankyo, Sumitomo Dainippon Pharma, Eisai, Eli Lilly, Janssen Pharmaceutical, Kyowa Hakko Kirin, Lundbeck, Meiji Seika Pharma, MSD, Mylan, Novartis Pharma, Ono Pharmaceutical,

Otsuka Pharmaceutical, Pfizer, Shionogi, Shire, Taisho Toyama Pharmaceutical, Takeda Pharmaceutical, Tanabe Mitsubishi Pharma, Tsumura, and Yoshitomi yakuhin, and has received research/grant support from Astellas, Daiichi Sankyo, Sumitomo Dainippon Pharma, Eisai, Eli Lilly, Kyowa Hakko Kirin, Mochida Pharmaceutical, MSD, Novartis Pharma, Otsuka Pharmaceutical, Pfizer, Shionogi, and Takeda Pharmaceutical. TA received research grant from Japan Agency for Medical Research and Development, research grant from Daiichi Sankyo, scholarship funds from Biotronik Japan, Medtronic Japan, Win International, Medical System Network, and Hokuyaku Takeyama Holdings, and honoraria from Daiichi Sankyo, Ono Pharmaceutical, Boehringer Ingelheim Japan, Bayer's Pharmaceuticals, and Bristol-Myers Squibb. KB and TN are employees of Sumitomo Dainippon Pharma. SI is an employee of CRECON Medical Assessment. CRECON Medical Assessment was paid from Sumitomo Dainippon Pharma to conduct analyses for the study. 


\section{Author details}

'Department of Psychiatry, Hokkaido University Graduate School of Medicine, Kita 15, Nishi 7, Kita-ku, Sapporo, Hokkaido, Japan. ${ }^{2}$ CRECON Medical Assessment Inc, 2-12-15, Shibuya, Shibuya-ku, Tokyo, Japan. ${ }^{3}$ Sumitomo Dainippon Pharma Co., Ltd., 13-1, Kyobashi 1-Chome, Chuo-ku, Tokyo, Japan. ${ }^{4}$ Department of Cardiovascular Medicine, Hokkaido University Graduate School of Medicine, Kita 15, Nishi 7, Kita-ku, Sapporo, Hokkaido, Japan.

Received: 10 September 2020 Accepted: 20 November 2020

Published online: 09 December 2020

\section{References}

1. GBD 2017 Disease and Injury Incidence and Prevalence Collaborators. Global, regional, and national incidence, prevalence, and years lived with disability for 354 diseases and injuries for 195 countries and territories, 1990-2017: a systematic analysis for the Global Burden of Disease Study 2017. Lancet. 2018;392(10159):1789-858. https://doi.org/10.1016/S01406736(18)32279-7.

2. The Ministry of Health, Labour and Welfare. [Japan's Mental Health Report]. http://www.mhlw.go.jp/kokoro/speciality/detail_into.html. Accessed 20 May 2020. Japanese.

3. Stahl SM, Muntner N. Stahl's essential psychopharmacology : neuroscientific basis and practical application. 4th ed. Cambridge: Cambridge University Press; 2013.

4. Japanese Society of Neuropsychopharmacology. [Guideline for Pharmacological Therapy of Schizophrenia]. http://www.asas.or.jp/jsnp/img/ csrinfo/togoshiccho_00.pdf. Accessed 20 May 2020. Japanese.

5. Hasan A, Falkai P, Wobrock T, Lieberman J, Glenthoj B, Gattaz WF, et al. World Federation of Societies of biological psychiatry (WFSBP) guidelines for biological treatment of schizophrenia - a short version for primary care. Int J Psychiatry Clin Pract. 2017;21(2):82-90. https://doi.org/10.1080/13651501. 2017.1291839.

6. Feng $\mathrm{S}$, Melkersson K. Metabolic parameters and long-term antipsychotic treatment: a comparison between patients treated with clozapine or olanzapine. Neuro Endocrinol Lett. 2012;33(5):493-8.

7. Roerig JL, Steffen KJ, Mitchell JE. Atypical antipsychotic-induced weight gain: insights into mechanisms of action. CNS Drugs. 2011;25(12):1035-59. https://doi.org/10.2165/11596300-000000000-00000.

8. Leucht S, Corves C, Arbter D, Engel RR, Li C, Davis JM. Second-generation versus first-generation antipsychotic drugs for schizophrenia: a metaanalysis. Lancet. 2009;373(9657):31-41. https://doi.org/10.1016/501406736(08)61764-X.

9. Kornetova EG, Kornetov AN, Mednova IA, Dubrovskaya W, Boiko AS, Bokhan $\mathrm{NA}$, et al. Changes in body fat and related biochemical parameters associated with atypical antipsychotic drug treatment in schizophrenia patients with or without metabolic syndrome. Front Psychiatry. 2019;10:803. https://doi.org/10.3389/fpsyt.2019.00803.

10. Chadda RK, Ramshankar P, Deb KS, Sood M. Metabolic syndrome in schizophrenia: differences between antipsychotic-naïve and treated patients. J Pharmacol Pharmacother. 2013;4(3):176-86. https://doi.org/10.4103/0976500x.114596.

11. JMDC Inc. https://www.jmdc.co.jp/. Accessed 20 may 2020. Japanese.

12. Keio University. [project result report of the 2010 Ministry of Health, Labour and Welfare Grant for comprehensive promotion project for welfare of persons with disabilities "estimate of the social cost of mental illness"]. 2011. Japanese.

13. Nishimura K, Okamura T, Watanabe M, Nakai M, Takegami M, Higashiyama A, et al. Predicting coronary heart disease using risk factor categories for a Japanese urban population, and comparison with the Framingham risk score: the Suita study. J Atheroscler Thromb. 2014;21(8):784-98. https://doi. org/10.5551/jat.Er19356.

14. D'Agostino RB Sr, Grundy S, Sullivan LM. Wilson P; CHD risk prediction group. Validation of the Framingham coronary heart disease prediction scores: results of a multiple ethnic groups investigation. JAMA. 2001;286(2): 180-7. https://doi.org/10.1001/jama.286.2.180.

15. Tanabe N, Iso H, Okada K, Nakamura Y, Harada A, Ohashi Y, et al. Serum total and non-high-density lipoprotein cholesterol and the risk prediction of cardiovascular events - the JALS-ECC. Circ J. 2010;74(7):1346-56. https://doi. org/10.1253/circj.cj-09-0861.
16. Ray WA, Chung CP, Murray KT, Hall K, Stein CM. Atypical antipsychotic drugs and the risk of sudden cardiac death. N Engl J Med. 2009;360(3):225-35. https://doi.org/10.1056/NEJMoa0806994.

17. PMDA. [Trial research on methods for assessing adverse event risks using health insurance claim data (2) Report]. 2014. Japanese.

18. Steyerberg EW, Vickers AJ, Cook NR, Gerds T, Gonen M, Obuchowski N, et al. Assessing the performance of prediction models: a framework for traditional and novel measures. Epidemiology. 2010;21(1):128-38. https://doi.org/10. 1097/EDE.0b013e3181c30fb2.

19. Kusumi I, Ito K, Honda M, Hayashishita T, Uemura K, Hashimoto N, et al. Screening for diabetes using Japanese monitoring guidance in schizophrenia patients treated with second-generation antipsychotics: a cross-sectional study using baseline data. Psychiatry Clin Neurosci. 2011; 65(4):349-55. https://doi.org/10.1016/j.pnpbp.2011.07.003.

20. Kusumi I, Arai Y, Okubo R, Honda M, Matsuda Y, Matsuda Y, et al. Predictive factors for hyperglycaemic progression in patients with schizophrenia or bipolar disorder. BJPsych Open. 2018;4(6):454-60. https://doi.org/10.1192/ bjo.2018.56.

21. Okumura Y, Ito H, Kobayashi M, Mayahara K, Matsumoto Y, Hirakawa J. Prevalence of diabetes and antipsychotic prescription patterns in patients with schizophrenia: a nationwide retrospective cohort study. Schizophr Res. 2010;119(1-3):145-52. https://doi.org/10.1016/j.schres.2010.02.1061.

22. Kanzaki T, Uju Y, Yoshimi T, Kobayashi E, Shiraishi K, Kondo T, et al. Differences in lifestyle-related diseases between schizophrenia and mood disorders. Chiba Survey Res J. 2017;6(1):12-20 Japanese.

23. Inamura $Y$, Sagae T, Kushida O, Nakamachi K, Murayama N. Survey of obesity and underweight among inpatients with schizophrenia in psychiatric hospitals throughout Japan. Seishin Shinkeigaku Zasshi. 2013; 115(1):10-21 Japanese.

24. Cheung S, Hamuro Y, Mahlich J, Nakahara T, Sruamsiri R, Tsukazawa S. Drug utilization of Japanese patients diagnosed with schizophrenia: an administrative database analysis. Clin Drug Investig. 2017;37(6):559-69. https://doi.org/10.1007/s40261-017-0517-0.

25. Someya Y, Tamura Y, Kohmura Y, Aoki K, Kawai S, Daida H, et al. A body mass index over $22 \mathrm{~kg} / \mathrm{m}^{2}$ at college age is a risk factor for future diabetes in Japanese men. PLoS One. 2019;14(1):e0211067. https://doi.org/10.1371/ journal.pone.0211067.

26. Meltzer HY, Bonaccorso S, Bobo WW, Chen Y, Jayathilake K. A 12-month randomized, open-label study of the metabolic effects of olanzapine and risperidone in psychotic patients: influence of valproic acid augmentation. J Clin Psychiatry. 2011;72(12):1602-10. https://doi.org/10.4088/JCP.10m05997.

27. Fleischhacker WW, McQuade RD, Marcus RN, Archibald D, Swanink R, Carson WH. A double-blind, randomized comparative study of aripiprazole and olanzapine in patients with schizophrenia. Biol Psychiatry. 2009;65(6):510-7. https://doi.org/10.1016/j.biopsych.2008.07.033.

28. Loebel A, Cucchiaro J, Xu J, Sarma K, Pikalov A, Kane JM. Effectiveness of lurasidone vs. quetiapine XR for relapse prevention in schizophrenia: a 12month, double-blind, noninferiority study. Schizophr Res. 2013;147(1):95102. https://doi.org/10.1016/j.schres.2013.03.013.

\section{Publisher's Note}

Springer Nature remains neutral with regard to jurisdictional claims in published maps and institutional affiliations.

Ready to submit your research? Choose BMC and benefit from:

- fast, convenient online submission

- thorough peer review by experienced researchers in your field

- rapid publication on acceptance

- support for research data, including large and complex data types

- gold Open Access which fosters wider collaboration and increased citations

- maximum visibility for your research: over $100 \mathrm{M}$ website views per year

At BMC, research is always in progress.

Learn more biomedcentral.com/submissions 